\title{
CARACTERÍSTICAS FÍSICAS, QUÍMICAS E MINERALOGICAS DE UMA CATENA DE SOLOS SOBRE FOLHELHO *
}

\author{
L. M. A. SANS ** \\ J. L. I. DEMATtÊ \\ A. Carvalho
}

RESUMO

Foram selecionados quatro perfis de solos localizados em uma catena sobre folhelho na região de Sete Iagoas, Estado de Minas Gerais. Os solos pertencem aos seguin' "grandes grupos: Bruno Avermelhado (Oxic Humitropept), Pr i 1 localizadr na posição de terras altas, Perfil 2 (Typic Paleustult) localizado na posição de pedimento de encosta e Latossol Vermelho Escuro (Typic Haplortox), Perfis 3 e 4 , localizados na posição de perlimento de sopé. O teor de silte é elevado e decresce dos Perfis 1 e 2 em direç̃̃o aos Perfis 3 e 4 , valores estes atribuílos a herança do material orginário.

Existe relação entre a posição que os solos ocupam na paisagem e as características estudadas. Solos mais férteis e con maior teores de silte e minerais de argila de grade $2: 1$ estão localizacios na posiçăo de terras altas e pedimentos de encosta enquanto que os menos férteis, de menores teores de silte e minerais de grade $2: 1$ estäo localizados na posição de pedimento de sopé. Os Bruno Ácidos são portanto mineralogicamente mais jovens do que os Latossois Vermelho Escuro.

A mica, parte da caulinita e montmorilonita são rr...crais provavelmente herdados do material de origem enquanto quo a gibbsita, parte da vermiculita e minerais interestratificados foram formarlos por pedogenese. A seguinte seqüência de intemperismo foi obtida, indo do solo menos evoluido ao mais evoluído: Bruno Acido (Perfis 1 e 2) < Latossol Vermelho Escuro (Perfil 3) < Latossol Vermetho Escuro (Perfil 4). Todos os perfis estudarlos são provenientes de material retrabalhado com contribuição de folhelho.

* Extra'do do trabalho de tese de M.S. "Classificação e Mineralogia de Solos da Região de Sete Lagoas - MG", - esentada a E.S.A. "Luiz de Queiroz", USP., Piracicaba. Entregue para puthlicaçäo em 25-03-1977.

* Instituto de Pesquisas Agropecuárias do Centro-Oeste, M.C.

*** Departamento de Solos e Geologia, E.S.A. "Luiz de Queiroz, U.S.P., Piracicaba.

**** Instituto de Geociências, USP., S. Paulo 


\section{INTRODUÇÃO}

O principal objetivo pretendido neste trabalho foi o de estudar as características granulométricas, químicas e mineralógicas de solos Bruno Ácidos e Latossois Vermelho Escuro supostamente originados de folhelho e localizados em posição catenária na região de Sete Lagoas, Minas Gerais.

Os Bruno Ácidos ou Brown Forest Soils de Tavernier e Smith (1957) são solos de clima temperado, morfologicamente pouco evoluídos, com uma seqüência de horizontes A, (B) e C, ácidos, de boa drenagem, baixa relação textural, baixa capacidade de troca catiônica, elevado teor de silte e coloração entre 10YR e 5YR. A Comissão de Solos (Brasil, 1963) na região de Furnas descreveu um solo semelhante ao classificado por Tavernier e Smith (1957) e designaram-no de solos Bruno Ácidos (similar) .

Apesar do grande valor agrícola que tanto o Bruno Ácido como o Latossol Vermelho Escuro apresentam para a região em estudo quase nada existe em relação aos dados de caracterização e mesmo de classificação destas unidades, informações estas imprescindíveis para uma adequada exploração agrícola.

\section{MATERIAL E MÉTODOS}

A área de estudo localiza-se na região de Sete Lagoas, Estado de Minas Gerais, no vale do Rio das Velhas, compreendida entre os rios Paraopeba e Cipó numa faixa delimitada ao norte pela latitude $19^{\circ} 10^{\prime}$ e ao sul pela latitude de $19^{\circ} 37^{\prime} 10^{\prime \prime}$.

Geologicamente a região em estudo situa-se na Série Bambuí dividida em Formação Rio Paraopeba, Sete Lagoas (de maior área de ocorrência no local) e Carrancas (Costa, 1963). Durante um período de sedimentação química na Formação Sete Lagoas, foram depositados cerca de $200 \mathrm{~m}$ de calcário, que na região de Prudente de Morais, nos níveis mais elevados ele aflora quase horizontalmente. Nos níveis inferiores o calcário é impuro e silicoso. Na parte superior da Série Bambuí (Formação Carrancas) a sedimentação clástica domina e logo acima do calcário vem uma camada de ardósia não calcífera, muitas vezes decomposta e com aspecto de folhelho (Branco, 1961) .

A área estudada é dominada por um vasto pediplano (Branco, 1961) com altitudes ao redor de $800 \mathrm{~m}$, relevo este elaborado após a deposição do Cretáceo Superior, durante o Terciário Inferior, através 
de aplainamento generalizado (ciclo erosivo Sul Americano) . Esta superfície apresenta topos de altitude concordante, com altitudes entre 700 e $850 \mathrm{~m}$. Esta superfície foi dissecada durante o ciclo erosivo Velhas por vales pouco profundos e representada em muitos pontos por altos terraços fluviais com cascalheiras.

O clima da região é classificado como Cwa segundo Koppen, sendo a média do mês mais quente superior a $22^{\circ} \mathrm{C}$ e a do mês mais frio superior a $18^{\circ} \mathrm{C}$. Apesar da eĩevada precipitação atmosférica $(1.300 \mathrm{~mm})$ há condições de aridez temporária devido a grande irregularidade da distribuição das chuvas associada a elevada evapotranspiração. O regime de umidade é ústico.

A vegetação predominante são os campos cerrados (Magalhães, 1963) e na região de estudo o desenvolvimento da vegetação acompanha o dos solos, encontrando-se sobre os solos mais evoiuídos uma vegetação mais densa e de maior porte, enquanto que nos solos pouco desenvolvidos predomina uma vegetação graminóide.

Foram coletados quatro perfis de solos em área localizada no município de Prudente de Morais segundo uma catena. O Perfil 1, Bruno Ácido, está localizado no topo da serra da Igrejinha a aproximadamente $820 \mathrm{~m}$ de altitude com grande quantidade de cascalho principalmente nos horizontes superficiais. A cor dos horizontes superficiais apresenta notação Munsell de 2,5Y 5/2 a 5/4, a dos horizontes B de 10YR $6 / 8$ e $7 / 8$ e os horizontes $C$ com notação $7,5 Y R$ 4/6 e presença de mosqueados. O Perfil 2, também um Bruno Ácido, está localizado na posição de pedimento de encosta a $750 \mathrm{~m}$ de altitude com presença de cascalho fino no horizonte Ap e fragmentos de folhelho no B1. A cor dos horizontes A é 10YR $5 / 4$ a $5 / 6$ passando a $7,5 \mathrm{YR} 6 / 6$ a $6 / 8$ no B e 5YR 6/8 no C. Os perfis 3 e 4, Latossol Vermelho Escuro, estão localizados na posição de pedimento de sopé a 1,2 e $3 \mathrm{~km}$ de distância do Perfil 2 e a 640 e $620 \mathrm{~m}$ de altitude respectivamente. As cores dos horizontes A é predominantemente 2,5YR $3 / 3$ a $3 / 4$ e dos horizontes B de 2,5YR $2 / 4$ a $3 / 6$.

As determinações químicas e granulométricas foram feitas de acordo com a metodologia preconizada por Vettori (1969). O Ca, $\mathrm{Mg}$ e Al com extração de $\mathrm{KCl} \mathrm{N}$, o $\mathrm{H}$ pelo acetato de cálcio a $\mathrm{pH} 7$, o $\mathrm{K}$ e $\mathrm{Na}$ pela extração com $\mathrm{HCl}$, o carbono orgânico pela oxidação da matéria orgânica com bicromato de potássio, o $\mathrm{SiO}_{2}$ e $\mathrm{Al}_{2} \mathrm{O}_{3}$ pelo ataque sulfúrico. A granulometria foi feita por peneiramento e sedimentação. Para a análise mineralógica da fração argila realizou-se o pré-tratamento das amostras de solos, remoção dos sais solúveis, oxidação da matéria orgânica e remoção ferro livre, segundo as recomendações de Jackson (1965a) . A identificação qualitativa dos minerais da fração argila foi 
realizada com aparelho de difração dos raios $\mathrm{X}$, com registro gráfico. Duas alícotas de cada amostra, isenta de ferro livre, foram saturadas respectivamente com íons de $\mathrm{K}^{+}$e $\mathrm{Mg}^{++}$, e em seguida colocadas sobre lâminas de vidro, tendo-se o cuidado de orientá-las preferencialmente, com o auxílio de uma espátula. A mesma lâmina contendo material saturado com íon $\mathrm{K}+$ foi examinada 3 vezes: após a secagem no meio ambiente, depois de aquecida a $350^{\circ} \mathrm{C}$ e a $550^{\circ} \mathrm{C}$. As lâminas saturadas com íon $\mathrm{Mg}++$ foi adicionada etileno glicol. A análise quantitativa da mica foi feita com base no teor de $\mathrm{K}_{2} \mathrm{O}$ (Alexiades e Jackson, 1966); a caulinita e a gibbsita por análise térmica diferencial (Dixon, 1966); a vermiculita e montmorilonita pela capacidade de troca catiônica (Alexiades e Jackson, 1965); a alofana por dissolução seletiva com $\mathrm{NaOH}$ 0,5N (Alexiades e Jackson, 1966).

\section{RESULTADOS E DISCUSSÃO}

\section{Propriedades granulométricas e químicas}

Os resultados granulométricos apresentados no Quadro 1 mostram que o teor de silte é elevado nos Perfis 1 e 2 decrescendo nos demais solos. O teor de silte do Perfil 1 aumenta de acordo com a profundidade do solo indo de $45 \%$ no horizonte $\mathrm{Al}$ a $64 \%$ no horizonte IIC3. Entre os horizontes (B3) e IIC1 ocorre um aumento brusco no teor deste separado (passa de 43 a $53 \%$ ) coincidindo com a presença de cascalho até a profundidade do (B3). Esta descontinuidade litológica também está evidenciada pelo teor de areia grossa (Quadro 1). Assim é que o teor médio deste separado nos horizontes superiores é de $12 \%$ enquanto que abaixo do horizonte IIC1 ele é de $2 \%$. Devido a esta descontinuidade litológica, considera-se que a parte superior do solo é formado por material diferente quando comparado com a parte inferior explicando, com isso, as diferenças nos teores de silte e de areia.

O Perfil 2, apesar de ter também um elevado teor de silte (média de $50 \%$ ), possue uma distribuição diferente quando comparado com o Perfil 1. Assim é que o teor deste separado decresce em profundidade, sugerindo, com isso, que o material de origem do Perfil 2 é retrabalhado.

Os Perfis 3 e 4 já possuem teores de silte mais baixos principalmente nos horizontes inferiores. Valores elevados deste separado nos Bruno Ácidos tem sido constatado por diversos autores, entre os quais, Brasil (1963), Baur e Lyford (1957). Entretanto, os Latossois Vermelho Escuro, são solos bem intemperizados e consequentemente de baixo teor de silte, como é o caso da unidade de mapeamento Latossol Vermelho 


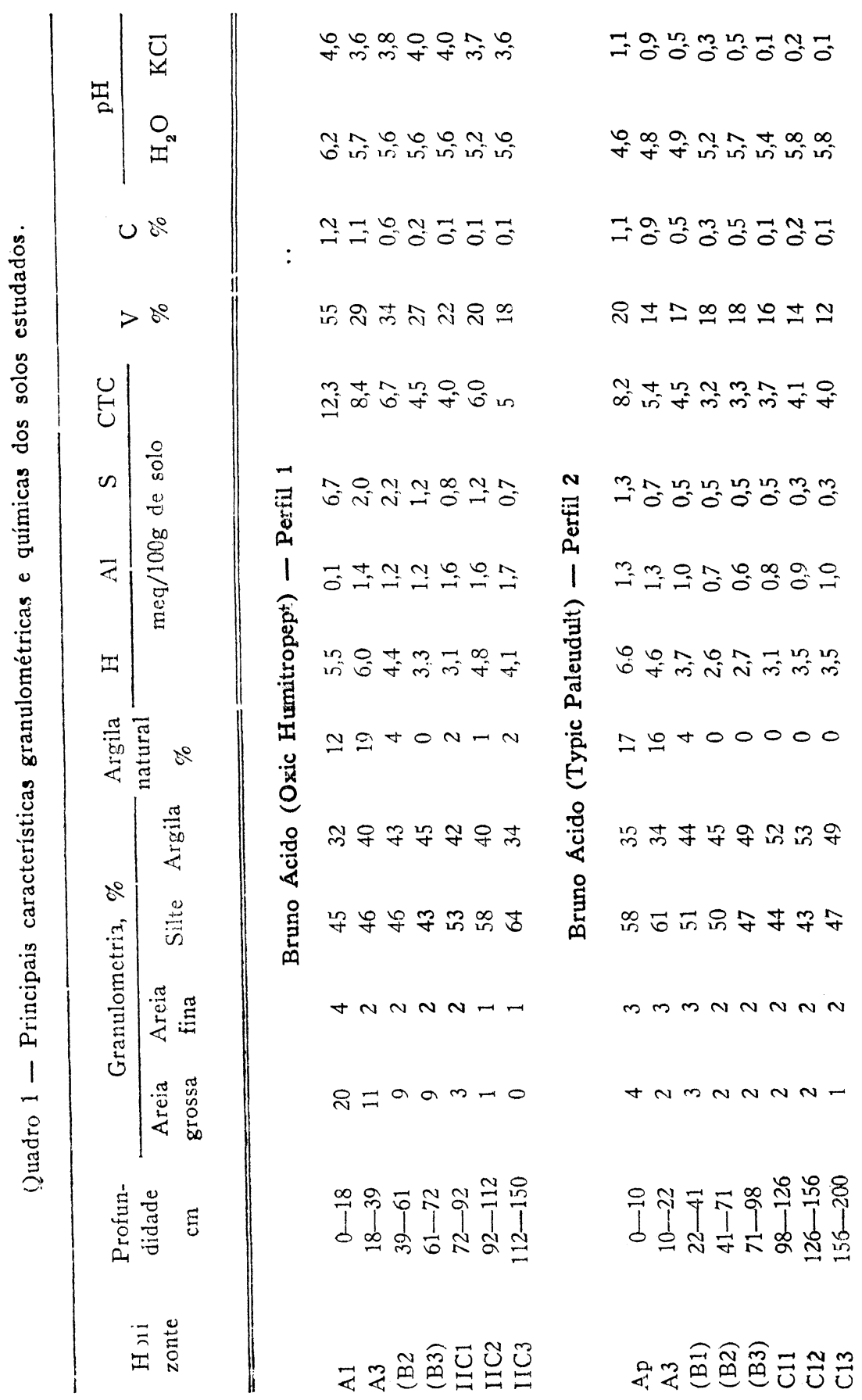




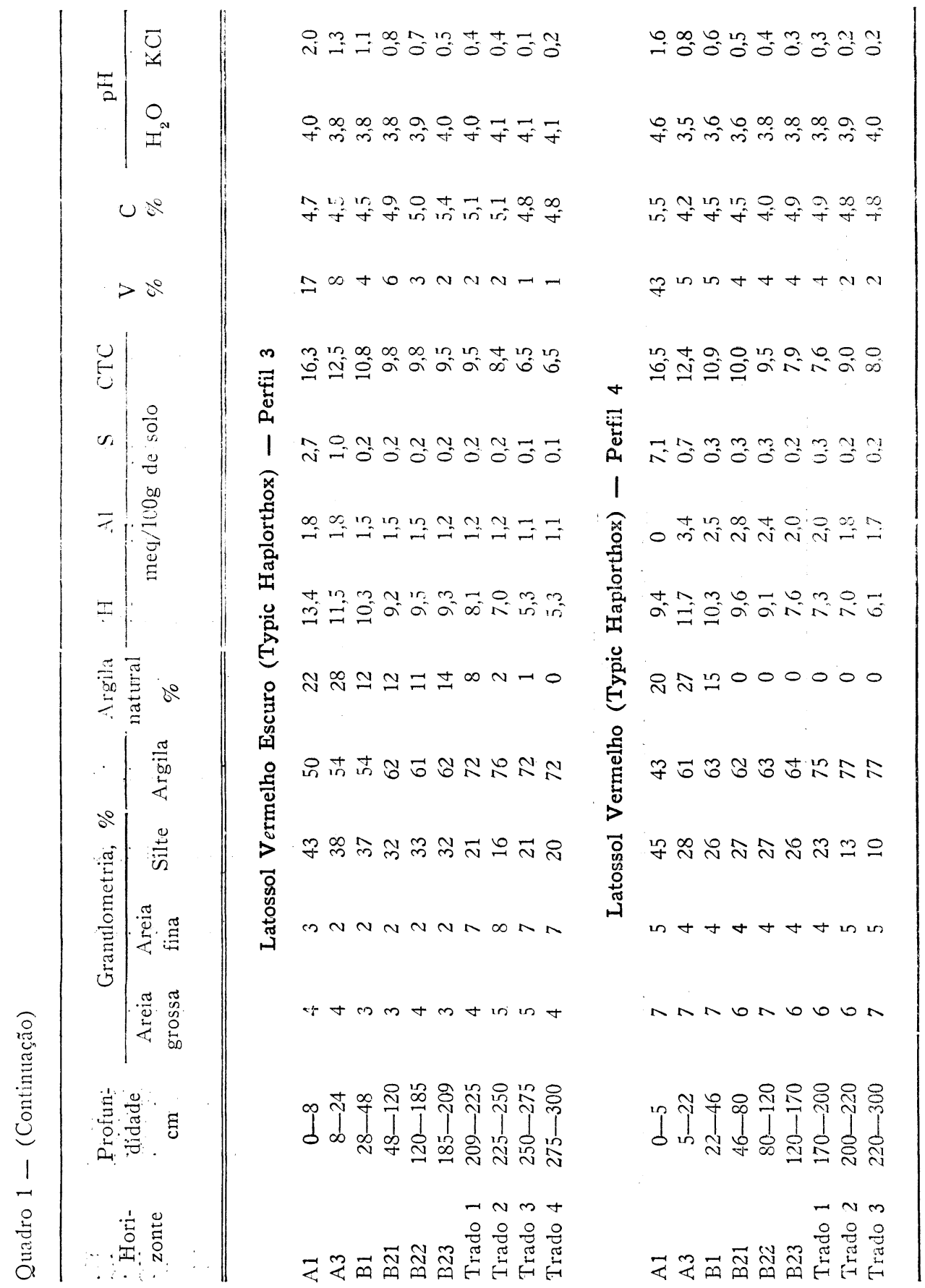


Escuro-Orto (Brasil, 1960) originado de argilito-folhelho. Os elevados teores de silte apresentado por tais solos na área de estudo se deve a herança do material originário.

De acordo com os dados obtidos apenas a parte inferior do Perfil 1 é supostamente originado in situ do folhelho sendo que a parte superior deste solo assim como os demais perfis são originados de material retrabalhado com contribuição de folhelho.

Esta contribuição do folhelho tende a diminuir da posição de terras altas e pedimento de encosta (Perfis 1 e 2 com teor médio de $50 \%$ de silte) para a posição de pedimento de sopé, no caso o Perfil 3, com $29 \%$ de silte e localizado a $1,2 \mathrm{~km}$ do Bruno Ácido e o Perfil $4 \mathrm{com} 23 \% \mathrm{de}$ silte localizado a $3 \mathrm{~km}$ do Bruno Ácido.

Os solos estudados são normalmente argilosos sendo que o teor deste separado tende a aumentar no Perfil 1 ao Perfil 4, concentrando-se nos horizontes inferiores. O elevado teor deste separado nos Perfis 3 e 4 se deve a um maior intemperismo destes solos quando comparados com os Bruno Ácidos. Apesar de haver uma pequena concentração de argila em profundidade há formação de horizonte argílico no Perfil 2 fato este também comprovado pela descrição morfológica que indicou ocorrência de cutan iluvial no horizonte (B2) .

Os teores de argila natural dos solos estudados decrescem de acordo com a profundidade do solo (Quadro 1), com valores mais elevados nos horizontes superficiais. Tal resultado é atribuído a influência da matéria orgânica como agente de dispersão de solos. Entretanto no Perfil 3 (Latossol Vermelho Escuro) o teor de argila natural é relativamente elevado até a profundidade de $225 \mathrm{~cm}$ sendo que o teor de carbono orgânico nesta profundidade é baixo, menor do que $0,5 \%$, o que não explicaria o elevado teor de argila natural. O teor argila em solos varia principalmente em função da quantidade de matéria orgânica, do valor do $\Delta \mathrm{pH}$ e da cristalinidade do ferro (Gilman, 1974). O que deve ter ocorrido no Perfil 3 é que devido ao elevado teor de argila silicatada (Quadro 2) os teores de óxidos de alumínio (gibbsita) e de ferro são baixos, não havendo, portanto, condições para formar microagregados estáveis. Consequentemente as argilas podem ficar dispersas.

Os dados químicos apresentados pelos solos estudados (Quadro 1) indicam que os perfis localizados nas posições mais elevadas do relevo (terras altas e pedimento de encosta) são quimicamente mais ricos do que os solos localizados nos pedimentos de sopé. Assim é que a saturação de bases e, consequentemente a soma de bases, decresce dos Bruno Ácidos (Perfis 1 e 2) para os Latossois Vermelho Escuro (Perfis 3 e 4). Isto se deve ao fato de serem os Perfis 3 e 4 mais lixiviados e intemperizados do que os demais solos. 
De uma maneira geral os solos são ácidos a muito ácidos e com valores de $\Delta \mathrm{pH}$ sempre negativos. Considerando os horizontes inferiores nota-se que os valores de $\Delta \mathrm{pH}$ são mais elevados nos Perfis 1 e 2 quando comparados com os Perfis 3 e 4 . Este resultado se deve a maior porcentagem de minerais de grade 2:1 (Quadro 2) encontrados nos primeiros solos.

Quadro 2 - Análise mineralógica quantitativa da fração argila de horizontes selecioilados de solos.

\begin{tabular}{|c|c|c|c|c|c|c|c|c|c|}
\hline $\begin{array}{l}\text { Hori- } \\
\text { zontes }\end{array}$ & $\begin{array}{l}\text { Profun- } \\
\text { didade } \\
\quad \mathrm{cm}\end{array}$ & $\begin{array}{l}\text { Cauli- } \\
\text { nita }\end{array}$ & $\begin{array}{l}\text { Gibbsi- } \\
\text { ta }\end{array}$ & Mica & $\begin{array}{l}\text { Vermi- } \\
\text { culita }\end{array}$ & $\begin{array}{l}\text { Mon- } \\
\text { tmori- } \\
\text { lonita }\end{array}$ & $\begin{array}{l}\text { Mate- } \\
\text { rial } \\
\text { Amor } \\
\text { fo }\end{array}$ & Toral & $\mathrm{Ki} *$ \\
\hline \multicolumn{10}{|c|}{$\%$} \\
\hline \multicolumn{10}{|c|}{ Bruno Ácido (Perfil 1) } \\
\hline $\mathrm{A} 1$ & $0-18$ & 51 & 0 & 27 & 4 & 9 & 8 & 99 & 1,9 \\
\hline (B2) & $39-61$ & 61 & 1 & 20 & 6 & 5 & 8 & 101 & 1,9 \\
\hline (B3) & $61-72$ & 69 & 1 & 18 & 5 & 3 & 4 & 100 & 1,9 \\
\hline IIC2 & $92-112$ & 55 & 0 & 31 & 7 & 0 & 8 & 101 & 2,2 \\
\hline IIC3 & $112-150$ & 44 & 0 & 36 & 6 & 4 & 10 & 100 & 2,5 \\
\hline \multicolumn{10}{|c|}{ Bruno Ácido APerfil 2) } \\
\hline Ap & $0-10$ & 65 & 0 & 17 & 3 & 4 & 6 & 95 & 2,9 \\
\hline (B1) & $22-41$ & 56 & 0 & 30 & 4 & 5 & 6 & 101 & 2,0 \\
\hline (B3) & $71-98$ & 60 & 0 & 29 & 3 & 4 & 6 & 102 & 2,0 \\
\hline $\mathrm{C} 11$ & $98-126$ & 44 & 0 & 25 & 17 & 6 & 5 & 97 & 2,1 \\
\hline $\mathrm{C} 12$ & $126-156$ & 44 & 0 & 19 & 15 & 3 & 11 & 92 & 1,8 \\
\hline \multicolumn{10}{|c|}{ Latossol Vermelho Escuro (Perfil 3) } \\
\hline A1 & $0-8$ & 51 & 3 & 17 & 7 & 3 & 7 & 88 & 1,8 \\
\hline B1 & $28-48$ & 65 & 5 & 6 & 8 & 2 & 5 & 91 & 1,7 \\
\hline $\mathrm{B} 21$ & $48-120$ & 61 & 3 & 6 & 14 & 4 & 3 & 93 & 2,0 \\
\hline B22 & $120-185$ & 63 & 3 & 7 & 12 & 1 & 3 & 89 & 2,0 \\
\hline $\mathrm{B} 23$ & $185-209$ & 61 & 4 & 9 & 16 & 0 & 5 & 95 & 2,0 \\
\hline \multicolumn{10}{|c|}{ Latossol Vermelho Escuro (Perfil 4) } \\
\hline A1 & $0-5$ & 50 & 25 & 2 & 9 & 0 & 7 & 93 & 1,2 \\
\hline B1 & $22-46$ & 54 & 31 & 2 & 10 & 0 & 7 & 104 & 1,2 \\
\hline B21 & $46-80$ & 47 & 32 & 3 & 10 & 0 & 6 & 98 & 1,2 \\
\hline $\mathrm{B} 23$ & $80-120$ & 46 & 17 & 2 & 12 & 0 & 5 & 82 & 1,2 \\
\hline B3 & $170-200$ & 50 & 12 & 2 & 12 & 1 & 9 & 87 & 1,3 \\
\hline
\end{tabular}

$\mathrm{Ki}$ do solo total 
A capacidade de troca catiônica decresce de acordo com a profundidade do solo e este fato parece correlacionar-se com o teor de matéria orgânica. Os teores de $\mathrm{H}$ e Al aumentam dos Solos Bruno Ácidos em direção aos Latossois Vermelho Escuro fato este atribuído a maior lixiviação destes solos.

Como a espessura do horizonte superficial do Perfil 1 é pequena $(18 \mathrm{~cm})$ e a cor deste mesmo horizonte é clara o epipedon diagnóstico definido é um ócrico (USA, 1975) . O horizonte diagnóstico de subsuperfície foi classificado como câmbico devido as seguintes características: ausência da estrutura da rocha matriz; presença de material intemperizável (folhelho) em quantidade superior a $5 \%$ e ausência de acúmulo de argila. As demais características, incluindo climáticas e químicas, permitiram a classificação deste solo no sub grupo Oxic Humitropepts. O Perfil 2 por apresentar horizontes argílico e ócrico, aliado com as características climáticas da região e com os dados granulométricos e químicos foi classificado como Typic Paleustult. O horizonte diagnóstico de subsuperfície dos Perfis 3 e 4 foi considerado como sendo óxido devido principalmente as características químicas e a presença de gibbsita (Quadro 2) que demonstra ter este solo um elevado grau de intemperismo. A classificação a nível de subgrupo para ambos os perfis foi Typic Haplorthox.

\section{Mineralogia da fração argila}

Os difratogramas referentes a fração argila do Perfil 1 estão apresentados na Figura 1A, onde nota-se a ocorrência de mica (espaçamento de $10 \AA$ inalterado pelos tratamentos), caulinita (espaçamento de $7,2 \mathrm{~A}$ eliminado a $550^{\circ} \mathrm{C}$ ) e montmorilonita (espaçamento na região dos 17A com glicolação). Além desses minerais ocorrem picos entre as regiões de 10 e $14 \mathrm{~A}^{\circ}$ indicando a presença de minerais interestratificados (Bradley, 1956) que de acordo com Mehara e Jackson (1959) pode ser classificado como interestratificação vermiculita-mica. A composição mineralógica do Perfil 2 é semelhante a do Perfil 1 (Figura 1B) diferindo, entretanto, com a do Perfil 3. Assim é que os picos da mica e dos minerais interestratificados diminuem de intensidade nos perfis de latossois havendo, entretanto, aumento de intensidade nos picos da caulinita. Foi ainda observada ocorrência de montmorilonita no Perfil 3 (Figura 1C) . A mineralogia do Perfil 4 é muito semelhante a do Perfil 3, evidenciando, entretanto, a ocorrência do pico a $4,85 \AA$ característico da gibbsita que desaparece com o aquecimento a $350^{\circ} \mathrm{C}$ (Fig. 1D) . 
Anais da E. S. A. "Luiz de Queiroz"
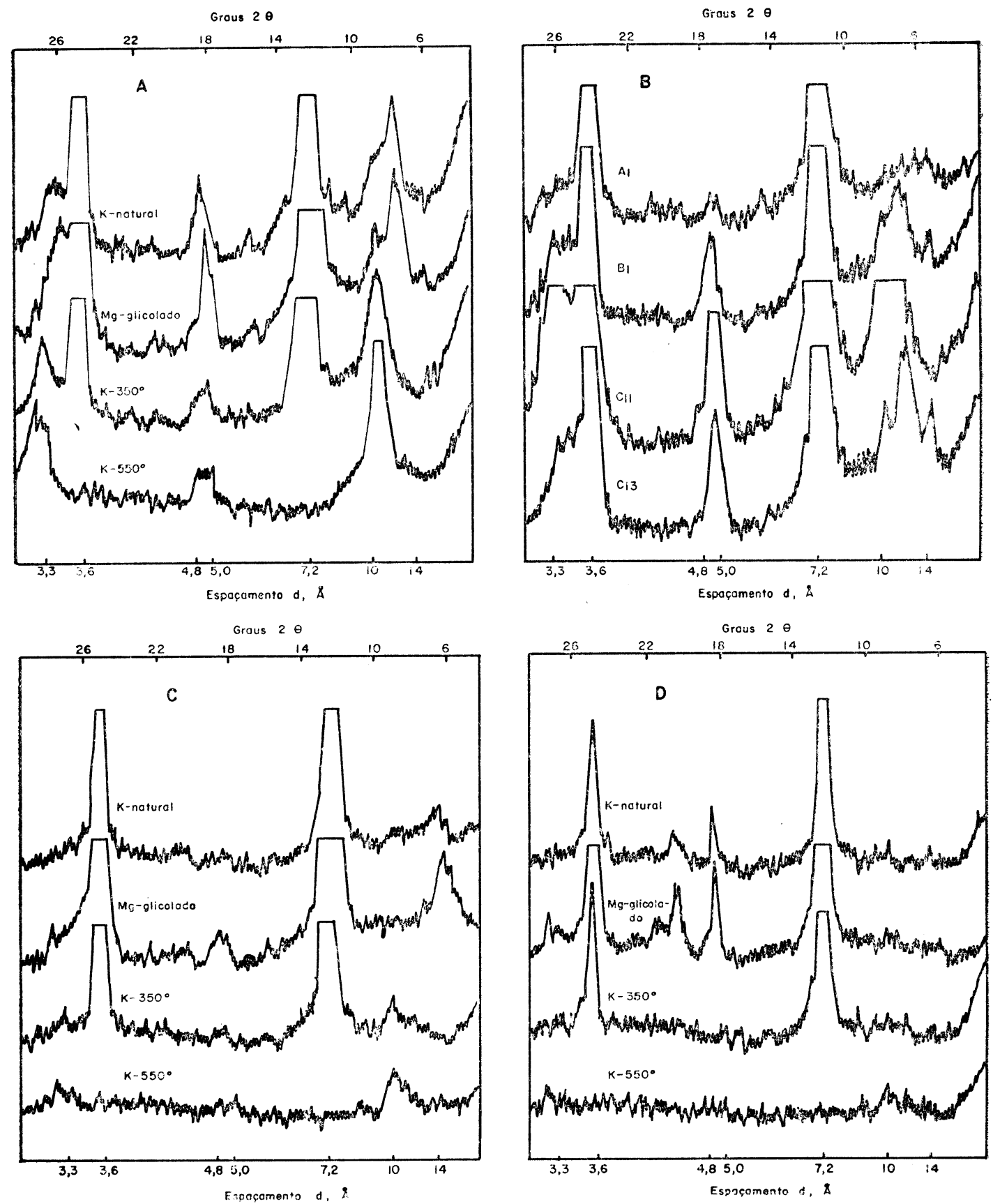

Figura 1. Difratogramas da fração argila: (A) horizonte (B2), Perfil 1; (B) Perfil 2; (C) Horizonte B23, Perfil 3; (D) Horizonte B1, Perfil 4. 
A caulinita é o mineral dominante nos horizontes A e B dos solos estudados (Quadro 2) com teores médios de $60 \%$ (Perfis 1,2 e 3) e de $50 \%$ para o Perfil 4 . O teor de minerais de grade $2: 1$ (vermiculita, mica e montmorilonita) decresce do Perfil 1 (média de 30\%) em direção ao Perfil 4 (média de 12\%), refletindo, com isso, as diferenças de intemperismo entre tais solos. Dentre os minerais de grade 2:1, a mica possue os valores mais elevados nos Solos Bruno Ácidos. A distribuição deste mineral, de acordo com a profundidade do solo, nos Perfis 1 e 2 não segue as generalizações de Jackson et alii (1948). Considerando-se o Perfil 1 nota-se que o teor de mica decresce até a posição do horizonte (B) aumentando, em seguida, nos horizontes inferiores. Uma possível explicação para tal fato seria o retrabalhamento do material de origem dos horizontes superficiais, o que é reforçado pelo elevado teor de cascalho existente nos horizontes A e B. Explicação semelhante pode ser aplicada ao Perfil 2 onde o máximo teor de mica é encontrado no horizonte (B1) que coincide com a presença de fragmentos de folhelho e cascalho fino nesta profundidade.

Os Perfis 3 e 4 (Latossol Vermelho Escuro) apresentaram composição mineralógica diferente dos Solos Bruno Ácidos refletindo uma maior ação do intemperismo nos latossois. O teor de minerais de grade 2:1 é relativamente baixo para os Perfis 3 e 4 com predominância da vermiculita (teor médio 10\%) havendo também ocorrência de gibbsita com teores médios de $3 \%$ para o Perfil 3 e $23 \%$ para o Perfil 4 .

A presença da vermiculita em solos tropicais tem sido relatada por diversos autores, entre os quais, Guerrero (1971), e Lepsch (1973), e tem sido atribuída ao intemperismo da mica (Borchardt, et alii, 1966) . Este fato pode ser verificado quando se compara os resultados do Quadro 1 onde o teor de mica decresce do Perfil 1 ao Perfil 4 enquanto que o da vermiculita cresce neste mesmo sentido. Ao contrário da mica a vermiculita é um mineral mais estável em condições de intensa lixiviação e baixo pH (Fields e Taylor, 1961), condíções estas semelhantes ao da região estudada.

Em vista da baixa resistência da mica ao intemperismo em comparação com a caulinita e vermiculita, a mica identificada nestes solos foi provavelmente herdada do material originário ao invez de ser sintetizada durante o presente ciclo pedogenético. Assim é que o teor mais elevado de mica foi encontrado no horizonte IIC3 (parte do material de origem) do Perfil 1. Por outro lado o decréscimo do teor deste mineral sugere uma transformação dele em outro, no caso a caulinita através da vermiculita.

A caulinita pode ter sido sintetizada durante a pedogenese assim como herdada do material originário. Prevalescendo condições do bai- 
xo pH e baixa saturação de bases, que são as condições atuais dos solos estudados, a caulinita normalmente se forma a partir de minerais de grade 2:1 através de processos envolvendo desilicatização e remoção de alumínio. A presença de gibbsita nos Perfis 3 e 4 e a ausência deste mineral nos horizontes $\mathbf{C}$ do Perfil 1 indica que ele foi formado por processos pedogenéticos através da dessilicatização da caulinita (Jackson, $1965 \mathrm{~b}$ ). Tal fato pode ser observado através dos resultados dos Perfis 3 e 4 (Quadro 1) onde o teor médio de caulinita (Perfil 3) é de $60 \%$ e o de gibbsita $4 \%$ enquanto que o Perfil 4 apresenta um teor médio de $50 \%$ de caulinita e $23 \%$ de gibbsita. Ou seja, houve uma diminuição de caulinita do Perfil 3 em direção ao Perfil 4 enquanto que a gibbsita aumentou neste mesmo sentido, sugerindo com isso a transformação de caulinita para gibbsita.

A quantidade de material amorfo é praticamente constante em profundidade com teores normalmente abaixo de $10 \%$. Na escala do intemperismo (Jackson et alii, 1948) este material ocupa o estádio 10 juntamente com a caulinita, podendo, portanto, atuar na formação de outros minerais menos ativos. A presença da montmorilonita nos solos estudados se deve a uma herança do material originário já que as atuais condições reinantes no solo, ou seja, solos ácidos, de boa drenagem e clima úmido são favoráveis a formação de caulinita e não de montmorilonita (Keler, 1964). A formação de minerais interestratificados em solos muito intemperizados (caso dos Perfis 3 e 4) se deve provavelmente a precipitação de hidróxidos e sesquióxidos de Al nos espaços interlamelares da vermiculita (Jackson, 1964). Através dos difratogramas apresentados na Figura 1 observa-se que a mica, de uma maneira geral, é um mineral mal cristalizado enquanto que a caulinita e gibbsita, principalmente nos Perfis 3 e 4, são minerais bem cristalizados.

De acordo com os dados mineralógicos, principalmente os teores de mica e gibbsita, os solos podem ser colocados na seguinte sequência de intemperismo, indo do menos evoluído ao mais evoluído:

\section{Bruno Ácido (Perfis 1 e 2) < Latossol Vermelho Escuro \\ (Perfil 3) < Latossol Vermelho Escuro (Perfil 4)}

A maior evolução mineralógica arpresentada pelos Perfis 3 e 4 se deve a alguns fatores entre os quais a posição que ocupam na paisagem a grande profundidade, a drenagem livre e as condições climáticas são considerados os mais importantes. A posição de pedimento de sopé ocupado pelos latossois condiciona uma superfície jovem, estável e praticamente plana favorecendo com isso a lixiviação e consequentemente, um maior intemperismo. Além destes fatos deve-se levar em consideração que o material de origem dos Perfis 3 e 4 são materiais retraba- 
lhados com contribuição de folhelho e que já sofreram pré-intemperismo. Por outro lado os Bruno Ácidos, localizados em posição de pedimento de encosta, em superfícies mais antigas porém instáveis estão sujeito a uma maior erosão fator este que atua na remoção da parte do material intemperizado. Consequentemente tais solos são ainda mineralogicamente jovens.

\section{CONCLUSÕES}

- Todos os perfis estudados são provenientes de material retrabalhado com contribuição de folhelho.

- O elevado teor de silte apresentado pelos solos foi considerado como herdado do material originário.

- Existe relação entre a posição que os solos ocupam na paisagem e o potencial químico. Solos mais férteis são os localizados na posição do pedimento de encosta enquanto que os menos férteis são localizados na posição de pedimento de sopé.

- Os Bruno Ácidos são solos mineralogicamente mais jovens do que os Latossois Vermelho Escuro, com grande quantidade de minerais de grade $2: 1$.

- A mica, parte da caulinita e montmorilonita são minerais provavelmente herdados do material de origem, enquanto que a gibbsita, parte da vermiculita e minerais interestratificados foram formados por pedogenese.

- A seguinte sequência de intemperismo foi obtida, indo do solo menos evoluído ao mais evoluído:

$$
\begin{aligned}
& \text { Bruno Ácido (Perfis } 1 \text { e 2) < Latossol Vermelho Escuro } \\
& \text { (Perfil 3) < Latossol Vermelho Escuro (Perfil 4) }
\end{aligned}
$$

SUMMARY

PHYSICAL, CHEMICAL AND MINERALOGICAL PROPERTIES OF A SOIL CATENA ON SHALE.

Four soils on a shale catena were studied in Sete Lagoas region, Minas Gerais State and theirs physical, chemical and mineralogical properties were studied. The soils belongs to the following great soil groups: Soils Bruns Acids (Oxic Humitropepts), Profile 1 located in 
upland Profile 2 (Typic Paleustult) located in pediment backslope and Dark Red Latosols (Typic Haplorthox) Profiles 3 and 4, located in pediment footslope. The silt content is high and it decreaces from Pedon 1 through Pedon 4, and it was inherited from parent material.

There is a relationship between soil properties and the position of the soils on the landscape. The contents of base saturation, silt and 2:1 clay minerals are higher in soils located on upland and pediment blackslope than soils located on pediment footslope. Soils Bruns Acids are mineralogicaly younger than Dark Red Latosols. Mica, kaolinite and montmorillonite were probably inherited from parente material. Gibbsite and vermiculite were formed during pedogenesis.

According to mica content the following weathering sequence is suggested, going from the least to the most weathered soils: Soils Bruns Acid (Profiles 1 and 2) $<$ Dark Red Latosol $($ Profile 3$)<$ Dark Red Latosol (Profile 4) .

In relation to genetic implication in the studied area a general conclution is drown that all soils have been developed from reworked parent material.

\section{LITERATURA CITADA}

ALEXIADES, C.A. \& JACKSON, M.L. - Quantitative determination of vermiculite in soils. Soil Sci. Soc. Amer. Proc. 29: 522-527. 1965.

AILXIADES, C.A. \& JACKSON, M.L. - Quantitative clay mineralogical analysis of soils and sediments. Clays and Clay Minerals. 14 th. Conf. Pergamon Press. New York, 1966.

BAUR, A.J., \& LYFORD, W.H. - Soils Bruns Acides of Northeastern United States. Soil Sci. Soc. Amer. Proc. 21: 535-536, 1957.

BORCHARDT, G.A., JACKSON, M.L., \& HOLE, F.D. - Expandible layer silicate genesis in soils depicted in mica pseudomorphs. Proc. Intern. Clay Conference. 1: 175-185, Israel Program. Sci. Trans. Jerusalen, 1966.

BRADLEY, W.F. - A regulary interestratified chlorite-vermiculite clay mineral. American Mineralogist. 41: 497-504, 1956.

BRANCO, J.J.R. et alii - Roteiro para a excursão Belo Horizonte-Brasília. XIV Congresso Brasileiro de Geologia, Escola de Engenharia da Universidade de Minas Gerais Publicação n. ${ }^{\circ} 15,119$ p. 1961.

BRASIL - Comissão de Solos do SNEPA - Levantamento de reconhecimento de solos do Estado de São Paulo. Ministério da Agricultura, Rio de Janeiro. Poletim 12. 634 p., 1960.

BRASIL, —Comissão de Solos. Levantamento de reconhecimento dos solos da região sob influência do reservatório de Furnas. Ministério da Agricultura, Rio de Janeiro. Boletim 13. 462 p., 1963.

COSTA, M.T. - Estrutura geológica dos cerrados. I Reunião Brasileira do Cerrado. Ministério da Agricultura. Boletim 15. 83-92, 1963. 
DIXON, J.B. - Quantitative analysis of kaolinite and gibbsite in soils by differential and selective dissolution methods. Clays and Clay Minerals. 14 th. National Conf. on Clays and Clay Mineral Proc. Pergamon Press. New York, 83-89, 1966.

FIELDS, M., TAYLOR, N.H. - Clay mineralogy of New Zeland soils. 5. Mineral coloids and genetic classification. New Zeland Journ. Sci. 4: 679-706, 1961.

GILLMAN, G.P. - The influence of net charge on water dispersible clay and sorbed sulphate. Aust. J. Soil Res. 12: 173-176, 1974.

of selected soil profiles. Ph. D. Dissertation. University of North Caroline at Roleigh, GUERRERO, R. - Soils of the colombian Lhanos orientales. Composition and classification 1971.

JACKSON, M.L., TYLER, S.A., WILLIS, A.L., BOURBEAN, O.A. \& PENNINGTOי, R.P. - Weatherin sequence of clay size minerals in soils and sediments. The Journ. of Phys. and Coll. Chem. 52: 1237-1261, 1948.

JACKSON, M.L. - Chemical composition of the soils. Chap 2: 91-241. In Chemistry of the Soils F.E. Bear ed. Reinhold Publ. Corp. New York, 1964.

JACKSON, M.L. - Soil Chemical Analysis. Advanced Cource Univ. of Wisconsin, Md., 991 p., 1965a.

JACKSON, M.L. - Clay transformation in soil genesis during the quaternary. Soil Sci., 99: $15-22,1965 \mathrm{~b}$.

KELLER, W.D. - Processes of origem and alteration of clay minerals. In Soil Clay Mineralogy. A Symposium. C.I. Rich and Kunze ed. University of North Caroline Press. 330 p., 1964.

LEPSCH, I.F. - 1973 - Genesis, Morphology and Classification of Soils in an Oxisol, Ultisol Toposequence in S. Paulo State, Brazil. M.S. Thesis. University of North Caroline, Rloleigh.

MAGALHÃES, G.M. - Fitogeografia do Estado de Minas Gerais. I. Reunião Brasileira de Cerrado. Ministério da Agricultura. Boletim 15: 69- 82.

MEHARA, O.P. \& JACSON, M.L. - Constancy of the sum of mica unit cell potassium surface and interlayer sorptions surface in vermiculiteillite clays. Soil Sci. Soc. Amer. Proc. 23: 101-105, 1959.

VETTORI, L. - Métodos de análise de Solo. Equipe de Pedologia e Fertilidade de Solo, M.A. Boletim Técnico n. ${ }^{\circ} 7$. Rio de Janeiro, 1969.

U.S.A. - Soil Survey Stafif. Soil Taxonomy: a basic system of soil classification for making and interpreting soil surveys. Agriculture Handbook no. 436. U.S. Government Printing Office, Washington D.C. 1975.

TAVERNIER, R. \& G.D. SMITH - The concept of Braunerd (Brown Forest Soil) in Europe and the United States. Advanced in Agronomv IX. 217-286. 
